\title{
Penataan Kampung Mrican dengan Metode Partisipatif
}

\author{
Adli Nibras Pramudia dan Wahyu Setyawan \\ Departemen Arsitektur, Fakultas Arsitektur, Desain dan Perencanaan, \\ Institut Teknologi Sepuluh Nopember (ITS) \\ e-mail:wahyu9san@gmail.com
}

\begin{abstract}
Abstrak-Dewasa ini kebutuhan hidup semakin lama semakin bertambah dan beraneka ragam. Pada dasarnya manusia akan memenuhi kebutuhan paling dasarnya terlebih dahulu sebelum memenuhi kebutuhannya dasar yang tingkatannya lebih tinggi.

Dalam hal ini banyak warga pinggiran yang mencoba mengadu nasib ke kabupaten Sleman membuat permasalahan baru pada sekitar daerah aliran sungai Gajahwong. Mereka yang datang mulai mendirikan bangunan di sekitar daerah aliran sungai Gajahwong yang mempunyai fungsi sebagai daerah serapan air hujan. Selain itu permasalahan berikutnya terkait dengan kurangnya interaksi sosial antar warga. Salah satu metode yang bisa dilakukan untuk mengatasi permasalahan warga Mrican adalah membangun bersama warga dengan metode partisipatif. Metode ini lebih menitikberatkan kepada partisipasi warga dengan tujuan dapat mempersiapkan diri mereka untuk nantinya berpindah ke tempat yang lebih aman dan nyaman. Sehingga ketika pemerintah desa ingin menggunakan tanah yang mereka tinggali, warga telah siap untuk pergi. Hasil desain pada kampung Mrican mencakup penambahan massa vertikal pada sebagian rumah dan sebagian lagi dilakukan peremajaan fasad sesuai dengan budaya lokal masyarakat setempat. Selain itu terdapat bank sampah dan sentra kerajinan guna meningkatkan perekonomian warga.
\end{abstract}

Kata Kunci-Keamanan Bermukim, Kebutuhan Dasar, Metode Partisipatif.

\section{PENDAHULUAN}

$\mathrm{F}$ ENOMENA permasalahan permukiman kumuh terjadi hampir di semua kota besar di Indonesia. Kabupaten Sleman sebagai salah satu wilayah yang diperhitungkan di Provinsi Daerah Istimewa Yogyakarta juga mengalami permasalahan serupa. Permasalahan ini dimulai dengan kenaikan jumlah imigran ke kabupaten Sleman sebagai dampak dari sudah tidak tertampungnya lagi imigran di kota Yogyakarta.

Ketika pertumbuhan jumlah penduduk tidak dibarengi dengan pertumbuhan ekonomi maka akan menimbulkan banyak permasalahan baru antara lain kekumuhan baru yang diikuti dengan buruknya interaksi sosial. Kekumuhan baru yang diakibatkan dari lemahnya ekonomi warga imigran (Gambar 1). Sedangkan buruknya interaksi sosial diakibatkan dari kurangnya sarana warga berinteraksi (Gambar 2).

Masalah tidak berhenti disitu saja tetapi ketika mereka bekerja dalam upaya pemenuhan kebutuhan, mereka juga menjadi kekurangan waktu untuk berkumpul dan melakukan kegiatan bersama. Dampaknya mereka tidak saling memahami karakter antara satu warga dengan warga lainnya.

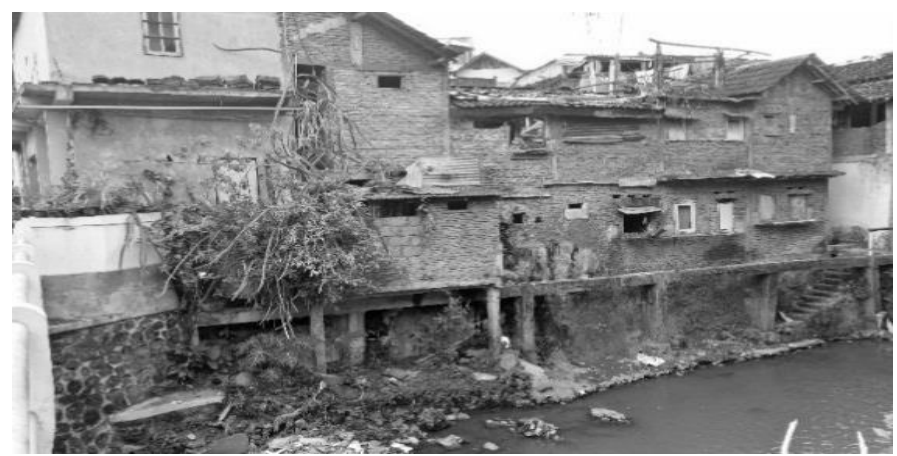

Gambar 1. Pola permukiman warga tidak tertata.

Sumber: Hasil Analisa, 2017

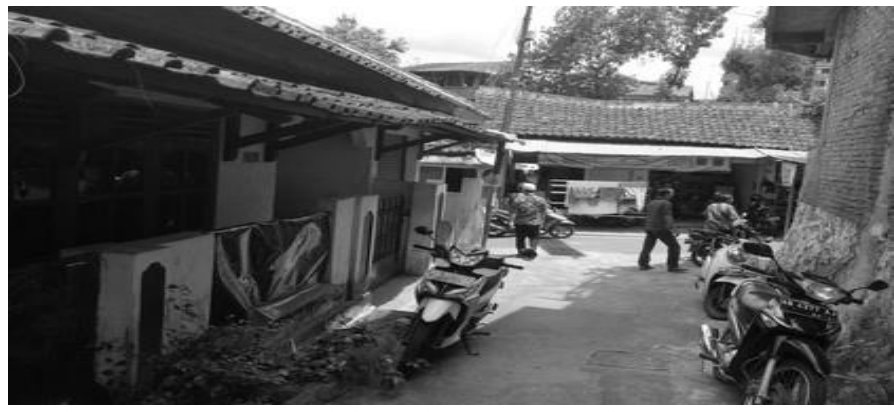

Gambar 2. Kurangnya interaksi sosial antar warga Mrican.

Sumber: Hasil Analisa, 2017

Data kependudukan Kabupaten Sleman menunjukkan bahwa jumlah penduduk di kecamatan Depok meningkat dengan pesat sehingga populasi penduduk per $\mathrm{km}^{2}$ paling tinggi di kabupaten Sleman (Tabel 1).

Sementara itu gini rasio di kabupaten Sleman cenderung tetap pada area perkotaan (Gambar 3). Dengan kepadatan penduduk yang tinggi serta gini rasio yang cenderung tetap akan berdampak pada timbulnya kekumuhan-kekumuhan baru di kabupaten Sleman.

\section{METODE DAN PENDEKATAN PERANCANGAN}

\section{A. Metode Partisipatif}

Menurut Davis (2002:142) partisipasi adalah keterlibatan mental dan emosional seseorang/individu dalam situasi kelompok yang mendorong dia untuk berkontribusi terhadap tujuan dan mempertanggungjawabkan keterlibatannya. Hal ini berarti pasrtisipasi adalah suatu gejala demokrasi dimana orang diikutsertakan dalam perencanaan serta dalam pelaksanaan dan juga ikut memikul tanggungjawab sesuai dengan tingkat kematangan dan tingkat kewajibannya [1]. 
Tabel 1.

Laju Pertumbuhan Pendudukan Kebupaten Sleman 2015

\begin{tabular}{|l|r|r|r|}
\hline \multicolumn{1}{|c|}{ Kecamatan } & Luas Wilayah & \multicolumn{1}{c|}{$\begin{array}{c}\text { Banyaknya } \\
\text { Penduduk }\end{array}$} & $\begin{array}{c}\text { Kepadatan } \\
\text { Penduduk per } \mathrm{km}^{2}\end{array}$ \\
\hline 1. Moyudan & 27.62 & 30.719 & 1.112 \\
\hline 2. Minggir & 27.27 & 20.954 & 1.062 \\
\hline 3. Seyegan & 26.65 & 46.869 & 1.760 \\
\hline 4. Godean & 26.84 & 70.754 & 2.636 \\
\hline 5. Gamping & 29.25 & 106.330 & 3.635 \\
\hline 6. Mlati & 28.52 & 111.180 & 3.898 \\
\hline 7. Depok & 35.55 & 185.707 & 5.224 \\
\hline 8. Berbah & 22.99 & 56.831 & 2.472 \\
\hline 9. Prambanan & 41.35 & 48.419 & 1.171 \\
\hline 10. Kalasan & 35.84 & 84.150 & 2.348 \\
\hline 11. Ngemplak & 35.71 & 64.187 & 1.797 \\
\hline 12. Ngaglik & 38.52 & 115.321 & 2.994 \\
\hline 13. Sleman & 31.32 & 66.567 & 2.125 \\
\hline 14. Tempel & 32.49 & 50.628 & 1.558 \\
\hline 15. Turi & 43.09 & 34.189 & 793 \\
\hline 16. Palem & 43.84 & 37.430 & 854 \\
\hline 17. Cangkringan & 47.99 & 29.246 & 609 \\
\hline Jumlah/Total & 574.82 & 1.167 .481 & 2.031 \\
\hline
\end{tabular}

Sumber: https://slemankab.bps.go.id/linkTabelStatis/view/id/38, 2015.

\section{Perkembangan gini ratio menurut daerah tempat tinggal di DI Yogyakarta}

Perkembangan gini ratio menurut daerah tempat tinggal di DI Yogyakarta

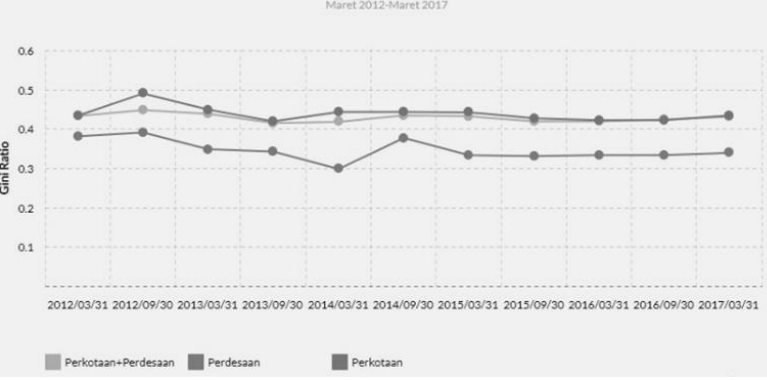

Gambar 3. Diagram Gini Ratio Provinsi DIY tahun 2014-2017.

Sumber: Badan Pusat Statistik Provinsi DIY, 2017

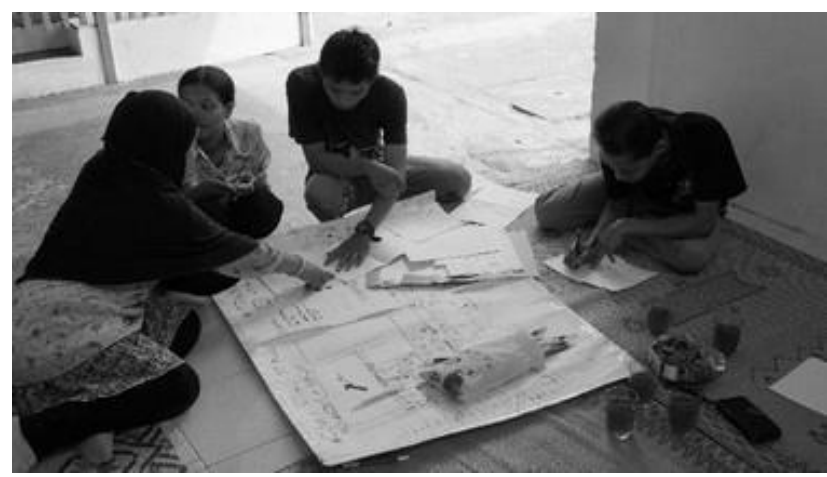

Gambar 4. Pemetaan Kampung Mrican bersama Warga dan Fasilitator Sumber: Hasil Analisa, 2017

Menurut Mikkelsen membagi partisipasi menjadi 6 (enam) pengertian, yaitu [2]:

1. Partisipasi adalah kontribusi sukarela dari masyarakat kepada proyek tanpa ikut serta dalam pengambilan keputusan.

2. Partisipasi adalah "pemekaan" (membuat peka) pihak masyarakat untuk meningkatkan kemauan menerima dan kemampuan untuk menanggapi proyek-proyek pembangunan.

3. Partisipasi adalah keterlibatan sukarela oleh masyarakat dalam perubahan yang ditentukannya sendiri.

4. Partisipasi adalah suatu proses yang aktif, yang mengandung arti bahwa orang atau kelompok yang terkait, mengambil inisiatif dan menggunakan kebebasannya untuk melakukan hal itu.

5. Partisipasi adalah pemantapan dialog antara masyarakat setempat dengan para staf yang melakukan persiapan, pelaksanaan, monitoring proyek, agar supaya memperoleh informasi mengenai konteks lokal, dan dampak-dampak sosial.

6. Partisipasi adalah keterlibatan masyarakat dalam pembangunan diri, kehidupan, dan lingkungan mereka.

Dari dua pakar yang mengungkapkan definisi partisipasi di atas, dapat dibuat kesimpulan bahwa partisipasi adalah keterlibatan aktif dari seseorang, atau sekelompok orang (masyarakat) secara sadar untuk berkontribusi secara sukarela dalam program pembangunan dan terlibat mulai dari pemetaan (Gambar 4), perencanaan (Gambar 5), perancangan (Gambar 6) hingga tahap evaluasi.

\section{B. Pendekatan Pembangunan Sosial}

Definisi pembangunan sosial menurut Midgley adalah suatu proses perubahan sosial yang terencana dan didesain untuk mengangkat kesejahteraan penduduk secara menyeluruh, dengan menggabungkannya dengan proses pembangunan ekonomi yang dinamis [3].

Menurut Todaro, ada tiga sasaran yang seyogyanya dicapai dalam pembangunan sosial, yaitu [4]:

1. Meningkatkan ketersediaan dan memperluas distribusi barang-barang kebutuhan pokok.

2. Meningkatkan taraf hidup, yaitu selain meningkatkan pendapatan, memperluas kesempatan kerja, pendidikan yang lebih baik, dan juga perhatian yang lebih besar terhadap nilai-nilai budaya dan kemanusiaan, yang keseluruhannya akan memperbaiki bukan hanya kesejahteraan material tetapi juga menghasilkan rasa percaya diri sebagai individu ataupun sebagai suatu bangsa.

3. Memperluas pilihan ekonomi dan sosial yang tersedia bagi setiap orang dan setiap bangsa dengan membebaskan mereka dari perbudakan dan ketergantungan bukan hanya dalam hubungan dengan orang dan negara lain tetapi juga terhadap kebodohan dan kesengsaraan manusia. Pembangunan, dengan demikian, harus dipahami sebagai suatu proses berdimensi jamak yang melibatkan perubahan-perubahan besar dalam struktur sosial, sikap masyarakat, dan kelembagaan nasional. 


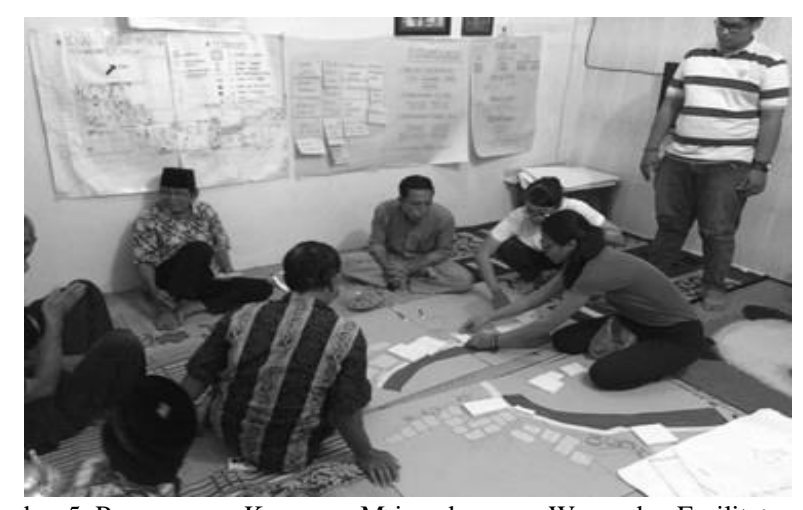

Gambar 5. Perencanaan Kampung Mrican bersama Warga dan Fasilitator Sumber: Hasil Analisa, 2017

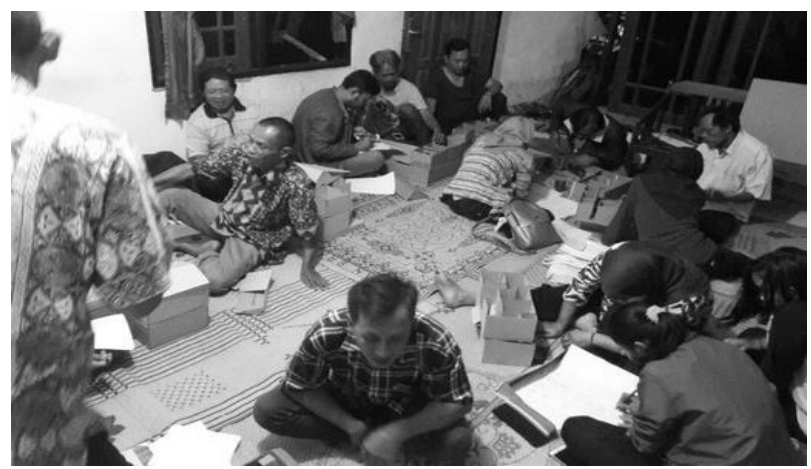

Gambar 6. Perancangan Kampung Mrican bersama Warga dan Fasilitator Sumber: Hasil Analisa, 2017

Tabel 2.

Perbandingan Material Rumah Warga Mrican

\begin{tabular}{|c|c|c|}
\hline Material & Bahan & Harga \\
\hline \multirow[t]{2}{*}{ Kolom Ukuran 0.2 x 0.2} & Besi Baja & Rp 203.150 \\
\hline & Beton & Rp 1.139.000 \\
\hline \multirow[t]{2}{*}{ Dinding Ukuran 1 x 1} & Bambu & 6.700 \\
\hline & Plester & Rp 100.000 \\
\hline \multirow[t]{2}{*}{ Atap Ukuran 1 x 1} & Fiber Cement & Rp $\quad 31.000$ \\
\hline & Tanah Liat & 45.000 \\
\hline
\end{tabular}

Sumber: Hasil Analisa, 2018

Dalam kaitannya dengan strategi pembangunan sosial yang dapat diterapkan dalam upaya meningkatkan taraf hidup masyarakat, Midgley mengemukakan ada tiga strategi besar, yaitu [3]:

1. Pembangunan sosial oleh individu, di mana kesejahteraan masyarakat secara keseluruhan dapat diangkat ketika para individu berusaha untuk mengangkat kesejahteraan mereka masing-masing. Pendekatannya lebih mengarah pada pendekatan individualis dan pendekatan enterprise (usaha).

2. Pembangunan sosial oleh masyarakat, di mana masyarakat saling bekerja sama secara harmonis serta memiliki tujuan yang sama untuk memenuhi kebutuhan mereka, memecahkan permasalahan mereka dan berusaha menciptakan kesempatan guna memperbaiki hidup. Pendekatannya lebih dikenal dengan nama pendekatan kemasyarakatan.

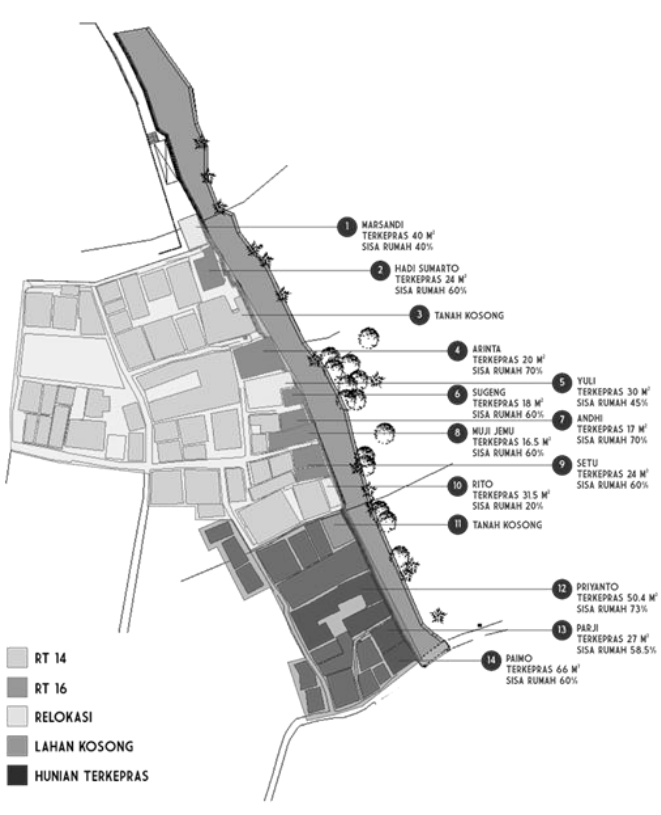

Gambar 7. Penetapan kriteria rumah terdampak.

Sumber: Arkom Jogja, 2017

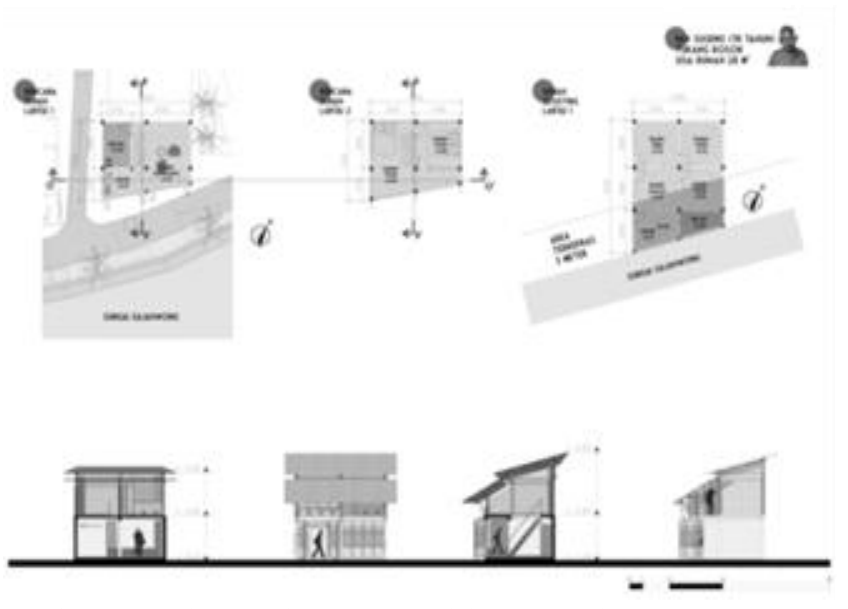

Gambar 8. Denah, tampak, potongan salah satu rumah warga.

Sumber: Hasil Analisa, 2018

3. Pembangunan sosial oleh pemerintah, di mana pembangunan sosial dilakukan oleh pemerintah, dengan agen-agennya yang khusus, pembuatan kebijakan, para perencana dan administraturnya. Negara mewakili kepentingan masyarakat secara keseluruhan dan memiliki tanggung jawab mengangkat kesejahteraan seluruh warganegaranya. Pendekatannya lebih dikenal dengan nama pendekatan statist / negara.

\section{Pendekatan Ekonomi}

Pendekatan ekonomi bertujuan agar dalam pemilihan bahan material bangunan warga akan mendapatkan bahan material yang murah dan mudah dibongkar-pasang. Caranya yaitu dengan membandingkan bahan material (Tabel 2).

Hal ini dilakukan sesuai dengan tujuan warga sebelumnya, yaitu berpindah ke tempat yang lebih aman dan nyaman. Dengan begitu maka material yang dipilih harus memiliki masa pakai yang tidak terlalu lama. 


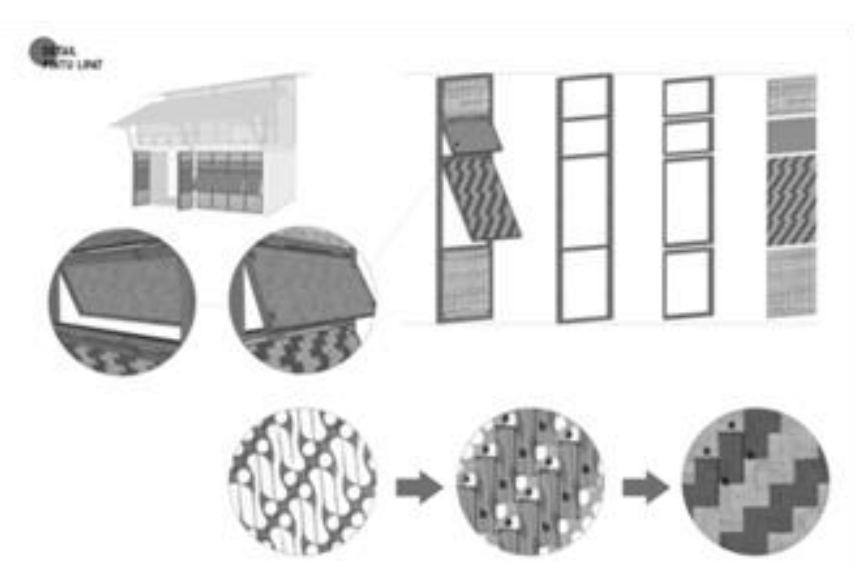

Gambar 9. Detail pintu lipat. Sumber: Hasil Analisa, 2018

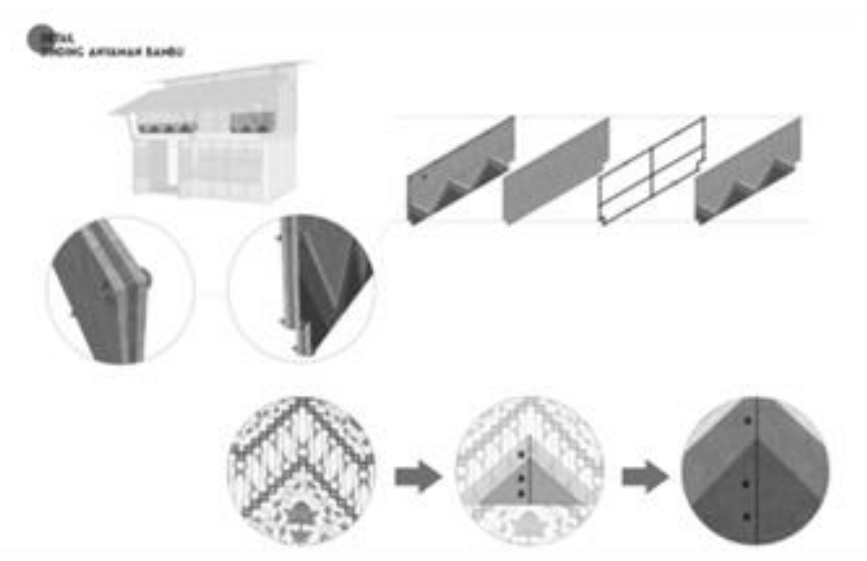

Gambar 10. Detail dinding anyaman bamboo.

Sumber: Hasil Analisa, 2018

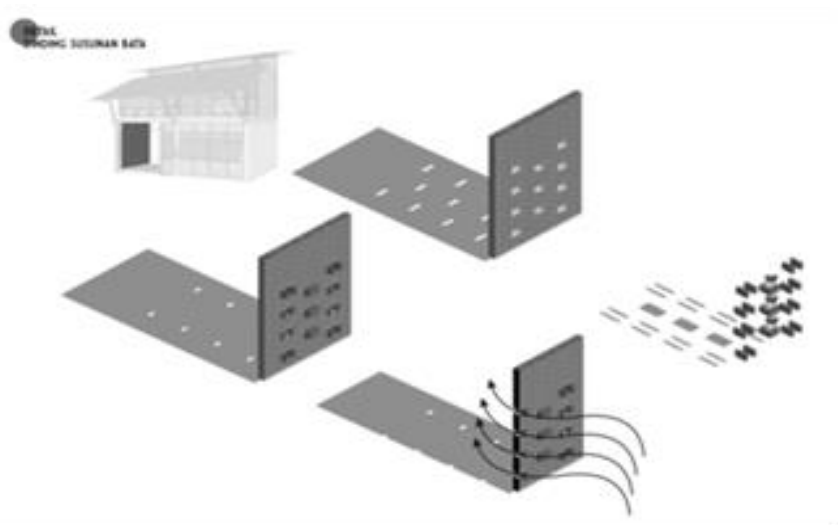

Gambar 11. Detail dinding susunan bata.

Sumber: Hasil Analisa, 2018

Dari perbandingan material kolom disimpulkan bahwa material kolom yang paling sesuai dengan kebutuhan warga Mrican adalah dengan menggunakan material besi pipa baja.

Sedangkan untuk perbandingan material dinding dapat disimpulkan bahwa material dinding yang paling sesuai dengan kebutuhan warga Mrican adalah dengan menggunakan material anyaman bambu.

Dan terakhir untuk perbandingan material atap dapat disimpulkan bahwa material atap yang paling sesuai dengan kebutuhan warga Mrican adalah dengan menggunakan material fiber cement.

\section{HASIL PERANCANGAN}

Proses penataan kampung Mrican didasarkan pada kriteria hunian terdampak (Gambar 7). Cakupan desain pada pembahasan kali ini hanya mengambil sebagian dari keseluruhan wilayah yang terdampak yaitu 2 RT yang luas wilayahnya \pm 0.5 hektar.

Menurut kriteria yang sudah ditetapkan terdapat 3 kriteria hunian yaitu relokasi, tanah kosong dan terkepras. Dari ketiga kriteria tersebut akan disesuaikan dengan kebutuhan warga Mrican guna mempercepat peningkatan perekonomian warga. Hasilnya terdapat 3 program desain utama, yaitu tanah bekas hunian terelokasi akan dipergunakan untuk fungsi relaksasi berupa taman, sedangkan tanah kosong akan dimanfaatkan untuk fungsi produksi serta hunian terkepras akan di re-desain secara spesifik sesuai dengan kebutuhan masing-masing warga yang terdampak.

Desain rumah warga akan tetap mempertahankan eksisting lantai 1 dengan penambahan lantai 2 jika diperlukan. Penambahan massa lantai 2 disesuaikan dengan besaran ruang yang terkepras (Gambar 8). Sedangkan untuk rumah warga yang tidak membutuhkan penambahan massa vertikal fasad rumahnya akan dipugar dan diremajakan sesuai dengan desain rumah warga lainnya agar tercipta suatu harmonisasi desain yang baik.

Desain atap rumah warga menggunakan model atap panggang-pe bertingkat dengan tujuan agar sirkulasi udara menjadi lebih lancar sehingga panas ruangan bisa diminimalisir. Bagian pintu dan jendela menjadi satu bagian pada rumah warga sehingga bisa dilipat dengan tujuan agar ruangan bisa diperlebar ketika dibutuhkan. Bagian dinding menggunakan material anyaman bambu sebagai sirkulasi udara. Bagian tangga menggunakan model tangga setengah langkah untuk menghemat ruang.

Pada bagian detail pintu lipat mengadopsi pola batik bermotif parang (Gambar 9). Parang menjadi pedoman utama untuk menentukan derajat kebangsawanan seseorang. Harapannya warga akan segera berdaya seperti halnya para bangsawan.

Pembuatan motif pada gedhek diaplikasikan dengan menggunakan cat. Hal ini mengacu pada keterbatasan pendanaan warga. Pada elemen gedhek yang lain difinishing tanpa motif dan hanya menggunakan car engan warna yang berbeda dengan cat pada gedhek bermotif. Hal ini bertujuan untuk mengkolaborasikan warna yang kontras sehingga dapat menghasilkan spectrum warna yang kuat.

Pada bagian dinding anyaman bambu mengadopsi pola batik bermotif grompol (Gambar 10). Grompol dalam kosakata Bahasa jawa memiliki arti berkumpul atau bersatu. Harapannya warga akan selalu bersatu.

Pembuatan motif pada gedhek diaplikasikan dengan menggunakan cat. Sedangkan pada elemen gedhek yang lain difinishing tanpa motif. Hal ini bertujuan untuk menunjukkan karakter asli dari bambu.

Pada bagian dinding susunan bata berdapat 2 pola susunan bata (Gambar 11). Pertama adalah pola susunan dengan 
rongga pada tengahnya. Hal ini berfungsi sebagai media sirkulasi udara. Pola kedua berupa susunan 4 bata vertikal yang berfungsi sebagai tempat untuk meletakkan sayuran organik.

Fungsi produksi pada kampung Mrican berupa bank sampah dan sentra kerajinan. Kedua bangunan tersebut menggunakan bambu sebagai material utamanya. Bambu dipilih karena melimpahnya material tersebut di sekitar kampung sehingga dapat menekan biaya angkut material.

Bank sampah berfungsi sebagai sarana warga untuk mengumpulkan sekaligus memilah dan mengolah sampah. Sampah organik akan diolah menjadi pupuk cair orgnaik yang nantinya berfungsi untuk memupuk sayuran organik yang ada di setiap rumah warga. Sedangkan sampah non organik akan dimanfaatkan untuk menjadi kerajinan tangan yang bernilai jual.

Sentra kerajinan berfungsi sebagai workshop sekaligus tempat pameran dari kerajinan tangan berbahan dasar sampah non organik. Selain itu sentra kerajinan juga berfungsi sebagai sarana berkumpul warga.

Kesederhanaan dan keunikan dari masing-masing material bangunan akan sangat terasa pada desain di kampung Mrican ini. Hal tersebut bertujuan agar nantinya ketika warga Mrican berpindah ke tempat yang lebih aman dan nyaman mereka masih bisa menggunakan material sebelumnya sehingga akan meminimalisir pengeluaran biaya pembangunan.

\section{KESIMPULAN/RINGKASAN}

Kontribusi nyata warga Mrican dalam perencanaan kampungnya membuat warga Mrican tidak perlu lagi beradaptasi dengan lingkungan baru. Hal ini dikarenakan hasil desain pada kampung ini merupakan kolaborasi antara warga dengan pendamping masyarakat.

Desain dari masing-masing elemen bangunan rumah terkesan unik karena menggunakan material yang ramah lingkungan, mudah didapat namun difinishing dengan tetap memperhatikan aspek budaya lokal masyarakat Yogyakarta.

Selain itu penggunaan material yang ramah lingkungan menjadikan kampung Mrican secara tidak langsung memiliki karakter kampung yang berbeda dari sebelumnya. Ketika sebelumnya kampung mereka dipandang sebagai kampung kota yang kumuh, maka setelah penerapan desain ini kampung mereka bisa dipandang sebagai kampung yang sangat memperhatikan aspek lingkungan.

\section{DAFTAR PUSTAKA}

[1] D. Keith, N. Strom, and John W, Perilaku dalam Organisasi Jilid 1. Jakarta: Erlangga, 2000.

[2] B. Mikkelsen, Metode Penelitian Partisipatoris dan Upaya-Upaya Pemberdayaan. Jakarta: Yayasan Pustaka Obor Indonesia, 1999.

[3] J. Midgley, Pembangunan Sosial, Perspektif Pembangunan dalam Kesejahteraan Sosial. Jakarta: Ditperta Islam, 2005.

[4] G. Goble, A. Frank., and Supratiknya, Mazhab Ketiga, Psikologi Humanistik Abraham Maslow. Yogyakarta: Kanisius, 1987. 